\section{JENIS RUANG PUBLIK DI KAMPUNG KOTA DAN SENSE OF COMMUNITY WARGANYA (KASUS: KAMPUNG KALI APURAN, JAKARTA BARAT)}

\author{
Rika Ulfa Noviantri, Hanny Wahidin Wiranegara ', Yayat Supriatna \\ Program Studi Perencanaan Wilayah dan Kota, Fakultas Arsitektur \\ Lanskap dan Teknologi Lingkungan, Universitas Trisakti, Jl. Kyai Tapa \\ No.1, Jakarta Barat, Indonesia
}

\author{
Jurnal Pengembangan Kota (2019) \\ Volume 7 No. 2 (191-198) \\ Tersedia online di: \\ http://ejournal2.undip.ac.id/index.php/jpk \\ DOI: $10.14710 / j p k .7 .2 .191-198$
}

\begin{abstract}
Abstrak. Kampung kota adalah permukiman tradisional yang tidak terencana dengan kompleksitas permasalahannya seperti kota. Kampung kota Kali Apuran di Jakarta Barat yang padat dan tidak teratur, serta secara sosial dihuni penduduk yang heterogen maka sense of community merupakan hal penting. Ruang publik adalah elemen yang dapat memfasilitasi tumbuhnya sense of community. Terdapat macam-macam ruang publik di kampung kota yang dimanfaatkan penghuni sebagai tempat aktivitas dan interaksi antarwarga. Tujuan penelitian ini adalah untuk mengetahui tingkat sense of community warga kampung kota Kali Apuran pada berbagai jenis ruang publik yang ada di dalamnya. Metode penelitian menggunakan survey angket, yang diambil secara acak. Hasil analisis menunjukkan bahwa berbagai jenis ruang publik di Kampung Kali Apuran memiliki tingkat sense of community yang sama, yakni pada tingkat sedang. Artinya bahwa semua jenis ruang publik memfasilitasi sense of community. Adapun persentasenya berturut-turut menurut responden adalah sebagai berikut: tepi sungai (74,1\%), jalan kecil/gang depan rumah (53,7\%), halaman sekolah (50\%) dan halaman masjid (40\%). Hasil tersebut menunjukkan pentingnya kehadiran ruang publik di kampung kota. Agar terjadi peningkatan sense of community diperlukan rekayasa sosial berupa peraturan bersama tentang pemanfaatan berbagai ruang publik yang ada di kampung kota. Dalam hal ini dibutuhkan kepemimpinan lokal yang kuat agar pemanfaatan ruang publik tidak mengarah pada arah yang sebaliknya.
\end{abstract}

Kata Kunci: Jenis ruang publik; Sense of community; Kampung kota; Kampung Kali Apuran

[Title: Type of Public Space in the Urban Kampong and Sense of Community of its Residents]. Urban kampong is an unplanned traditional settlement with the complexity of problems like a city. Urban Kampong of Kali Apuran in West Jakarta is dense and irregular, as well as socially inhabited by heterogeneous populations, so the sense of community is important. Public space facilitates the growth of a sense of community. There are various public spaces in an urban kampong used by residents as a place for doing activities and interactions between them. The purpose of this study was to determine the level of a sense of community of various types of public spaces in Kampung Kali Apuran. The research method used a questionnaire survey, which is taken randomly. The results of the analysis showed that various types of public spaces in Kampung Kali Apuran have the same medium level of a sense of community. This means that all types of public spaces facilitate a sense of community. The percentages according to respondents are as follows: river bank (74.1\%); small road/alley in front of the house (53.7\%); schoolyard (50\%); and mosque yard (40\%). These results indicate the importance of the presence of public space in an urban kampong. To increase the sense of community, social engineering is needed in the form of a community regulation regarding the use of various public spaces in an urban kampong. In this case, strong local leadership is needed so that the utilization of public space does not lead in the opposite direction.

Keywords: Type of public space; Sense of community; Urban kampong; Kampung Kali Apuran

Cara Mengutip: Noviantri, R. U., Wiranegara, H. W., \& Supriatna, Y. (2019). Jenis Ruang Publik di Kampung Kota dan Sense of Community Warganya (Kasus: Kampung Kali Apuran, Jakarta Barat). Jurnal Pengembangan Kota. Vol 7(2): 191-198. DOI: 10.14710/jpk.7.2.191-198 


\section{PENDAHULUAN}

Makin baik kondisi lingkungan termasuk ruang publiknya, makin memperkuat rasa kebersamaan atau sense of community (Talen, 2000). Sense of community merupakan suatu hubungan sosial yang melibatkan interaksi di dalam suatu masyarakat, sehingga di dalamnya menimbulkan rasa saling memiliki (McMillan \& Chavis, 1986).

Kampung kota umumnya diidentikan dengan kondisi ketidakteraturan, ketidakseragaman, ketidakamanan, dan atau ketidaksehatan. Hal ini ditunjukkan oleh bentuk rumah tidak teratur, lebar gang yang sempit serta kurangnya sarana dan prasarana di dalamnya (Kristiani \& Yuliastuti, 2013). Kampung kota merupakan permukiman tradisional di pusat kota juga dapat mewakili kompleksitas permasalahan kota. Sebagai skala permukiman yang lebih mikro, dapat dijumpai adanya heterogenitas etnis, agama, pekerjaan, dan status sosial ekonomi di kampung kota di Jakarta (Prabowo, 2002). Dalam sebuah lingkungan yang

cenderung heterogen dibutuhkan rasa kebersamaan (Rogers dan Sukoratanametee dalam Kristiani \& Yuliastuti, 2013).

Pada dasarnya masyarakat membutuhkan ruang atau wadah aktivitas bersama dan berinteraksi sosial. Namun pada kampung kota, sebagai permukiman tak terencana, ketersediaan ruang publik terbatas. Di kampung kota, ruang publik seperti gang, warung atau kios, halaman terbuka dan lapangan dimanfaatkan sebagai tempat interaksi antar warga (Rahmi, et al., 2001 dalam Hutama, 2018). Francis, Giles-Corti, Wood, dan Knuiman (2012) meneliti hubungan antara empat jenis ruang publik, yaitu ruang terbuka publik, balai warga, sekolah, toko dengan sense of community atau rasa kebersamaan antarpenghuni pada skala area perkotaan metropolitan. Sujatini, Soemardi, Alamsyah, dan Linda (2015) menyatakan bahwa pemanfaatan ruang publik di kampung kota diperluas ke beberapa area, seperti jalan, gang, dan halaman kosong untuk memenuhi kebutuhan

\section{ISSN 2337-7062 @ 2019}

This is an open access article under the CC-BY-NC-ND license (http://creativecommons.org/licenses/by-nc-sa/4.0/). - lihat halaman depan (C) 2019

*Email hanny.w@trisakti.ac.id

Diterima 29 Oktober 2019, disetujui 29 November 2019 penghuni terhadap ruang publik.

Ruang publik memiliki nilai sosial budaya. Selain menyangkut tata ruang fisik lingkungan, peran ruang publik bagi masyarakat kampung kota mengemban fungsi dan makna sosial dan kultural yang sangat tinggi (Anita, Gustya, Erawati, \& Sukma, 2013; Ashadi, Anisa, \& Nur'aini, 2018; Talen, 2000). Ruang publik dapat memfasilitasi pertemuan antar tetangga (Francis et al., 2012; Talen, 2000) sehingga, menjadi pusat interaksi sosial yang dilakukan masyarakat, digunakan dalam melayani kebutuhan sosial dan dapat memberikan pengetahuan kepada para pelakunya (Widiananda, 2018). Juga secara umum dapat diinterpretasikan sebagai ruang milik bersama (Said \& Alfiah, 2017). Dengan demikian, pada kampung kota sebagai permukiman padat, maka ruang publik yang memadai untuk mewadahi aktivitas warga sangatlah penting.

Ruang publik adalah elemen yang dapat memfasilitasi tumbuhnya sense of community. Terwujudnya sense of community berpengaruh pada partisipasi warga dalam bentuk dukungan sosial atau peran aktif dan hadir memberikan kontribusi dalam masyarakat (Khusairi, Nurhamida, \& Masturah, 2017; Sumintarsih \& Adrianto, 2014). Ruang publik di kampung kota diharapkan dapat memperkuat struktur sosial masyarakat dengan membangun struktur kelembagaan maupun solidaritas di dalam masyarakat (Mulyandari \& Bhayusukma, 2015).

Terjadi perubahan ciri-ciri kampung dari yang semula bersifat pedesaan dengan penduduk yang homogen berubah menjadi rumah-rumah yang padat dengan penduduk yang heterogen, terutama di dekat pusat kota (Geertz dalam Haryadi dalam Prabowo, 2002), seperti Kampung Kali Apuran, Jakarta Barat. Penduduk Kampung Kali Apuran bersifat heterogen, mereka memanfaatkan ruangruang publik yang terdapat di lingkungan huniannya untuk mewadahi kegiatan antar warga. Kampung ini berada di lingkungan yang memiliki ketidakteraturan bentuk permukiman, keberagaman, dan ketidakamanan yang memerlukan sense of community untuk memperbaiki kondisi tersebut.

Berbagai penelitian pada berbagai kampung kota di Jakarta menunjukkan bahwa kebutuhan ruang publik untuk memenuhi kebutuhan interaksi sosial diperluas ke beberapa area yang dapat mewadahi kegiatan bersama (Ashadi et al., 2018; Sujatini et 
al., 2015). Oleh karena itu, pertanyaan yang ingin dijawab adalah: Seberapa besar tingkat sense of community penghuni Kampung Kali Apuran pada masing-masing jenis ruang publik yang ada di dalamnya?

\section{METODE PENELITIAN}

Penelitian ini menggunakan pendekatan kuantitatif dalam mengukur tingkat sense of community pada masing-masing jenis ruang publik yang terdapat di Kampung Kali Apuran. Untuk mengukur tingkat sense of community digunakan empat variabel sebagai unsurnya, meliputi keanggotaan (membership), pengaruh (influence), integrasi dan pemenuhan kebutuhan (integration and fulfillment of needs), serta hubungan emosional (shared emotional connection) seperti yang dikemukakan oleh McMillan dan Chavis (1986). Ke empat variabel tersebut diturunkan ke dalam beberapa indikator seperti diperlihatkan pada Tabel 1.

Tabel 1. Variabel dan Indikator Sense of Community

\begin{tabular}{|c|c|}
\hline Variabel & Indikator \\
\hline \multirow{3}{*}{$\begin{array}{l}\text { Membership } \\
\text { (Keanggotaan) }\end{array}$} & $\begin{array}{l}\text { Mengenali sebagian besar anggota } \\
\text { komunitasnya }\end{array}$ \\
\hline & $\begin{array}{l}\text { Meluangkan waktu dan upaya untuk } \\
\text { komunitasnya }\end{array}$ \\
\hline & $\begin{array}{l}\text { Memiliki simbol keanggotaan } \\
\text { komunitasnya (seperti pakaian, } \\
\text { tanda, kesenian, arsitektur, logo, } \\
\text { landmark, dan bendera) yang } \\
\text { dikenali. }\end{array}$ \\
\hline \multirow{2}{*}{$\begin{array}{l}\text { Influence } \\
\text { (Pengaruh) }\end{array}$} & $\begin{array}{l}\text { Individu memiliki pengaruh dalam } \\
\text { komunitas }\end{array}$ \\
\hline & $\begin{array}{l}\text { Ikut menyelesaikan masalah dalam } \\
\text { komunitasnya }\end{array}$ \\
\hline \multirow{3}{*}{$\begin{array}{l}\text { Integration } \\
\text { and } \\
\text { fulfillment of } \\
\text { needs } \\
\text { (Integrasi dan } \\
\text { pemenuhan } \\
\text { kebutuhan) }\end{array}$} & $\begin{array}{l}\text { Anggota komunitas memiliki } \\
\text { kebutuhan, prioritas, dan tujuan yang } \\
\text { sama }\end{array}$ \\
\hline & $\begin{array}{llr}\text { Dapat membicarakan } & \text { masalah } \\
\text { anggota dengan anggota } & \text { lainnya } \\
\text { dalam komunitas } & & \\
\end{array}$ \\
\hline & $\begin{array}{l}\text { Keberhasilan memenuhi kebutuhan } \\
\text { anggotanya }\end{array}$ \\
\hline $\begin{array}{l}\text { Shared } \\
\text { emotional }\end{array}$ & $\begin{array}{l}\text { Warga memiliki kepedulian pada } \\
\text { sesama anggota komunitas }\end{array}$ \\
\hline
\end{tabular}

\begin{tabular}{|l|l|}
\hline \multicolumn{1}{|c|}{ Variabel } & \multicolumn{1}{c|}{ Indikator } \\
\hline $\begin{array}{l}\text { connection } \\
\text { (Hubungan } \\
\text { emosional) }\end{array}$ & $\begin{array}{l}\text { Melakukan kegiatan bersama, seperti } \\
\text { liburan, perayaan hari raya, festival, } \\
\text { atau jika ada bencana }\end{array}$ \\
\cline { 2 - 2 } & $\begin{array}{l}\text { Merasa senang bersama anggota } \\
\text { komunitas lainnya }\end{array}$ \\
\hline
\end{tabular}

Sumber: McMillan dan Chavis (1986)

Jenis ruang publik yang diteliti di kampung kota Kali Apuran meliputi jalan kecil/gang, fasilitas sosial, lapangan/halaman terbuka, dan tepi sungai sesuai dengan keberadaannya di lapangan. Sense of community dapat diukur pada level rukun tetangga. Oleh karena itu, di dalam penelitian ini dipilih satu sampel rukun tetangga yang ada di kampung Kali Apuran yang memiliki variasi jenis ruang publik di dalamnya paling lengkap. Sebaran jenis ruang publik yang diteliti diperlihatkan pada Gambar 1. Lokasi penelitian adalah Kampung Kali Apuran RT 13 RW 07, Kelurahan Kedaung Kali Angke, Kecamatan Cengkareng, Jakarta Barat.

Metode penelitian digunakan survey angket. Pertanyaan disusun dengan menggunakan skala Likert. Angket disebarkan secara acak pada pengguna ruang publik di Kampung Kali Apuran pada weekdays dan weekend di pagi, siang dan sore hari yang disebar di tempat tinggal responden.

Teknik pengambilan sampel menggunakan simple random sampling, yaitu pengambilan sampel secara acak. Argumentasinya adalah secara umum penghuni Kampung Kali Apuran merupakan pendatang, dengan lama tinggal rata-rata sama. Berdasarkan lama huni yang homogen tersebut maka dapat diasumsikan sense of community tidak dipengaruhi oleh lamanya menghuni sehingga dapat disebar secara acak.

Banyaknya sampel 96 yang ditentukan dengan menggunakan rumus Lemeshow sebagai berikut:

$n=\frac{z^{2} p(1-p)}{d^{2}}$

$n=\frac{1.96^{2}(0.5)(1-0.5)}{(0.10)^{2}}=96$

Keterangan:

$\mathrm{n}=$ jumlah sampel; $\mathrm{z}=1.96$

$p=$ maksimal estimasi $=0.5$

$\mathrm{d}=\operatorname{alpha}(0.10)$ 

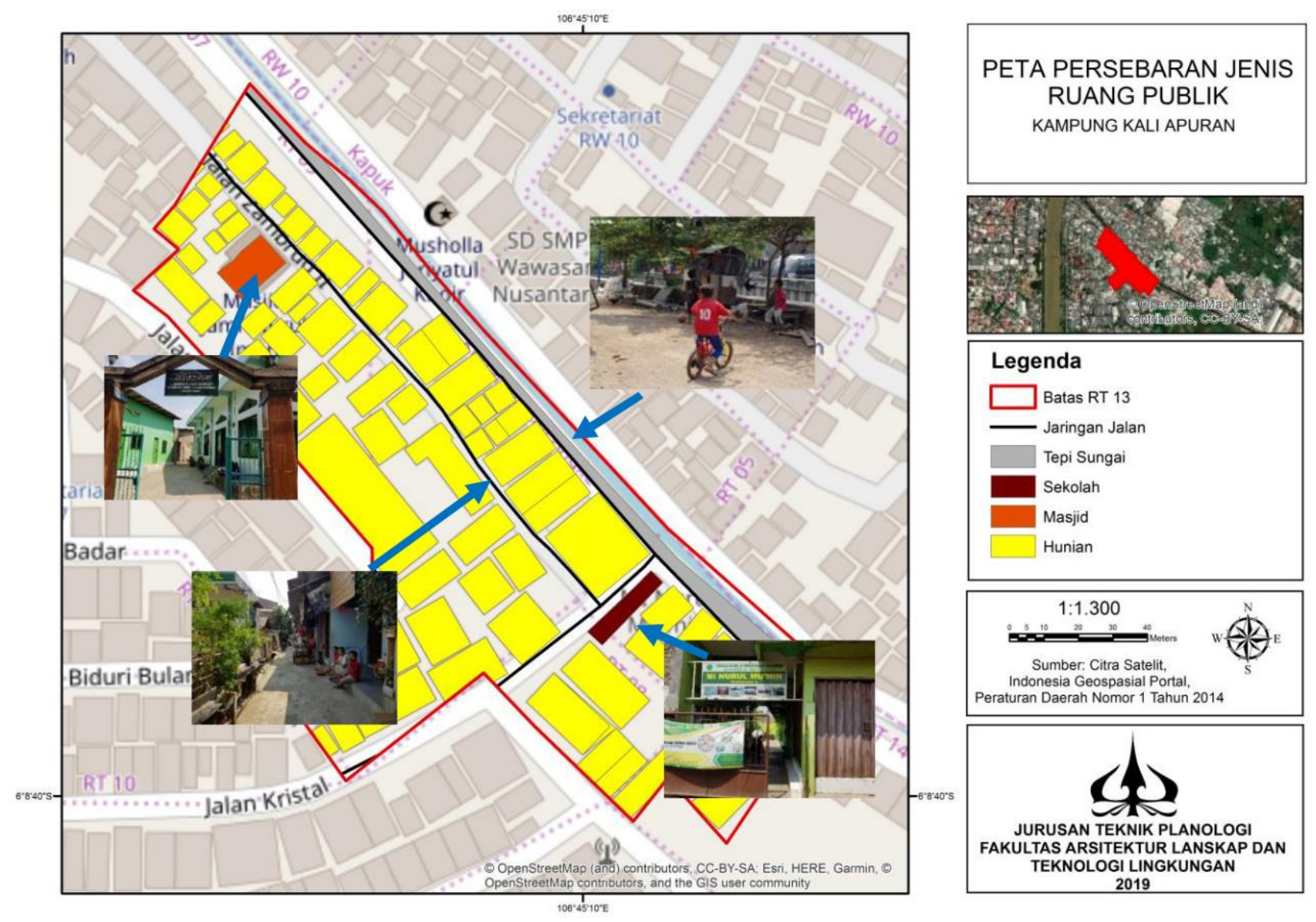

Gambar 1. Peta Persebaran Jenis Ruang Publik di Kampung Kali Apuran

Untuk mengetahui tingkat validitas data yang diperoleh dari jawaban angket digunakan uji statistik korelasi bivariat. Sementara uji reliabilitas digunakan untuk mengetahui konsistensi pertanyaan angket dalam mengukur hal yang ingin diukur. Untuk teknik analisis digunakan statistika deskriptif untuk mengkategorikan tingkat sense of community menjadi tiga kelas, yaitu rendah, sedang, dan tinggi pada masing-masing jenis ruang publik yang diteliti.

\section{HASIL DAN PEMBAHASAN}

Menurut Ashadi et al. (2018), dalam permukiman, kegiatan bersama dapat diwadahi dalam ruang bersama atau ruang publik. Pada permukiman padat kampung kota dengan terbatasnya ruangruang yang dimiliki pribadi maka peran ruang publik sangat besar. Menurut Hutama (2018) walaupun ruang terbuka di kampung kota terbatas, ruang publik untuk berinteraksi berlimpah, seperti gang atau jalan kecil, warung atau kios, MCK umum, fasilitas social (balai warga, pos keamanan, aula, masjid). Hal ini juga dinyatakan oleh Hickman (2013) mengenai ruang publik lokal atau yang ia sebut "third places" seperti warung kopi, kios, warung, dan balai warga sebagai ruang interaksi antarpenghuni. Sujatini et al. (2015) menyatakan bahwa untuk memenuhi kebutuhan ruang publik, pemanfaatan ruang publik di kampung kota diperluas ke beberapa area, seperti jalan, gang, dan halaman kosong. Jenis ruang publik yang digunakan warga Kampung Kali Apuran adalah jalan kecil/gang, fasilitas sosial, lapangan/halaman terbuka, dan tepi sungai.

\subsection{Tingkat Sense of Community Berbagai Jenis Ruang Publik di Kampung Kali Apuran}

Ruang publik di kampung kota yang memfasilitasi kegiatan penghuni dapat membangun sense of community antar mereka. Di Kampung Kali Apuran, tingkat sense of community masing-masing jenis ruang publik berdasarkan unsur-unsur sense of communitynya diperlihatkan pada Tabel 2 . 
Tabel 2. Tingkat Sense of Community berdasarkan Unsur-unsurnya di Berbagai Jenis Ruang Publik di Kampung Kali Apuran

\begin{tabular}{|c|c|c|c|c|c|}
\hline \multirow{2}{*}{\multicolumn{2}{|c|}{$\begin{array}{l}\text { Tingkatan Unsur } \\
\text { Sense of } \\
\text { Community (\%) }\end{array}$}} & \multicolumn{4}{|c|}{ Jenis ruang publik } \\
\hline & & \multirow{2}{*}{$\begin{array}{r}\text { Gang } \\
3,0\end{array}$} & \multirow{2}{*}{$\begin{array}{r}\text { HIm } \\
\text { Msjd } \\
5\end{array}$} & \multirow{2}{*}{$\begin{array}{r}\mathrm{HIm} \\
\text { Sklh } \\
0\end{array}$} & \multirow{2}{*}{$\begin{array}{l}\begin{array}{l}\text { Tepi } \\
\text { Sungai }\end{array} \\
74,1\end{array}$} \\
\hline Keanggotaan & $\mathrm{R}$ & & & & \\
\hline & $S$ & 52,2 & 60 & 100 & 20,4 \\
\hline & $\mathrm{T}$ & 44,8 & 35 & 0 & 5,6 \\
\hline \multirow[t]{3}{*}{ Pengaruh } & $\mathrm{R}$ & 11,9 & 25 & 75 & 11,1 \\
\hline & $\mathrm{S}$ & 58,2 & 55 & 12,5 & 64,8 \\
\hline & $T$ & 29,9 & 20 & 12,5 & 24,1 \\
\hline \multirow{3}{*}{$\begin{array}{l}\text { Integrasi \& } \\
\text { pemenuhan } \\
\text { kebutuhan }\end{array}$} & $\mathrm{R}$ & 11,9 & 25 & 25 & 20,4 \\
\hline & $S$ & 68,7 & 70 & 75 & 74,1 \\
\hline & $\mathrm{T}$ & 19,4 & 5 & 0 & 5,6 \\
\hline \multirow{3}{*}{$\begin{array}{l}\text { Hubungan } \\
\text { emosional }\end{array}$} & $\mathrm{R}$ & 3,0 & 0 & 37,5 & 5,6 \\
\hline & $S$ & 49,3 & 60 & 37,5 & 37 \\
\hline & $\mathrm{T}$ & 47,8 & 40 & 25 & 57,4 \\
\hline \multirow{3}{*}{$\begin{array}{l}\text { Tingkat } \\
\text { Sense of } \\
\text { community }\end{array}$} & $\mathrm{R}$ & 26,9 & 35 & 37,5 & 18,5 \\
\hline & $\mathrm{S}$ & 53,7 & 40 & 50 & 74,1 \\
\hline & $\mathrm{T}$ & 19,4 & 25 & 12,5 & 7,4 \\
\hline
\end{tabular}

Sumber: Hasil Kompilasi, 2019

(Keterangan: $\mathrm{R}=$ rendah (37-49); $\mathrm{S}=$ sedang (45-55); $\mathrm{T}=$ tinggi (53-60)

Di Kampung Kali Apuran, pada semua jenis ruang publik memiliki tingkat sense of community pada kategori sedang. Pada sel-sel dalam Tabel 2 tampak terdapat perbedaan pola tingkat sense of community pada jenis ruang publik tepi sungai. Pada unsur hubungan emosional lebih tinggi dibanding ruang publik lainnya, sementara pada unsur keaggotaan lebih rendah dibanding jenis ruang publik lainnya. Karakteristik ruang dan pemanfaatan ruang publik tepi sungai berbeda dengan ruang publik lainnya, karena ia dipakai juga di malam hari.

Area tepi sungai dijadikan sebagai salah satu ruang aktivitas karena memiliki lebar memadai untuk mewadahi kegiatan penghuni. Area ini mampu mengakomodasi interaksi sosial yang terjadi untuk menandakan kelekatan pada tempat (place attachment) di kampung kota (Hutama, 2018). Area tepi sungai cukup dekat dengan lokasi rumah warga, sehingga warga dapat mengaksesnya dengan mudah. Kegiatan yang biasa dilakukan para penghuni di area tepi sungai di antaranya adalah berbincang-bincang pada malam hari, berolahraga setiap hari Minggu, bermain anak-anak, dan kegiatan lomba-lomba dalam perayaan hari kemerdekaan. $\mathrm{Di}$ area tersebut terdapat tempat duduk yang memfasilitasi warga dalam berinteraksi.
Dengan area tepi sungai yang cukup lebar, maka warga dapat memanfaatkannya untuk melakukan kegiatan-kegiatan yang melibatkan banyak warga, seperti kegiatan lomba-lomba dalam perayaan hari kemerdekaan, senam pagi bersama pada hari Minggu.

Penghuni yang biasa beraktivitas di tepi sungai adalah laki-laki berusia 19-30 tahun yang mayoritas bekerja sebagai karyawan swasta. Pada setiap hari Minggu ibu-ibu bersenam pagi. Mayoritas penghuni pengguna tepi sungai beraktivitas di sini selama 1-2 jam dalam sehari dengan intensitas waktu beraktivitas 2-3 kali dalam seminggu. Dengan gambaran tersebut, area tepi sungai merupakan ruang publik di Kampung Kali Apuran yang mampu mengakomodasi interaksi sosial penghuni kampung yang melibatkan semua strata usia dan status.

Jalan di kampung kota merupakan unsur penting dalam kehidupan komunitas kampung (Putera, 2014). Jalan merupakan salah satu faktor yang mempengaruhi rasa kebersamaan (Talen, 1999 dalam Kristiani \& Yuliastuti, 2013). Di Kampung Kali Apuran, jalan kecil/gang depan rumah selain untuk sirkulasi, digunakan juga sebagai tempat interaksi sosial secara spontan. Rasa kebersamaan yang tinggi terjadi pada jalan dengan lebar berkisar antara 1,5-4,5 meter, sedangkan tingkat rasa kebersamaan rendah terjadi pada jalan dengan lebar 4-7 meter (Kristiani \& Yuliastuti, 2013). Jadi makin sempit lebar jalan makin tinggi rasa kebersamaan antar penghuni.

Lebar gang di Kampung Kali Apuran berkisar 1-1,5 meter sehingga penghuni memungkinkan untuk saling berkomunikasi. Ibu-ibu rumah tangga biasanya berbincang-bincang dengan tetangga depan rumah. Hal ini dimungkinkan karena selain jarak yang dekat juga mereka memiliki waktu luang. Penghuni yang biasa beraktivitas di gang depan rumah adalah ibu rumah tangga berusia 3140 tahun. Mereka umumnya menghabiskan waktu selama 1-2 jam dalam sehari. Frekuensi waktu berkumpul antar tetangga di gang depan rumah umumnya 2-3 kali dalam seminggu, walaupun tidak sedikit penghuni yang memiliki frekuensi 4-5 kali dalam seminggu atau bahkan lebih dari 5 kali dalam seminggu. Hal ini memungkinkan karena ibu-ibu rumah tangga berada di rumah. Gambaran ini menunjukkan bahwa gang depan rumah memfasilitas terbentuknya sense of community di Kampung Kali Apuran. 
Dengan keterbatasan ruang di Kampung Kali Apuran, maka halaman sekolah pun digunakan sebagai tempat beraktivitas warga dan mengakomodasi interaksi sosial pada waktu tidak terselenggara kegiatan belajar mengajar. Sifat ruang publik halaman sekolah adalah terbuka dan tertutup, artinya memanfaatkan ruang dan halaman terbuka dari sekolah Anita et al. (2013). Halaman sekolah di Kampung Kali Apuran dapat diakses oleh penduduk karena pagar yang jarang ditutup pada siang hari, sehingga biasa digunakan oleh ibu rumah tangga untuk berbincang-bincang atau dipakai anak-anak untuk bermain. Ibu rumah tangga yang biasa berkumpul di halaman sekolah berusia 31-40 tahun. Mereka menghabiskan waktunya sekitar 1-2 jam dalam sehari di waktu libur sekolah.

Halaman masjid digunakan warga Kampung Kali Apuran sebagai tempat berinteraksi dengan keterbatasan ruang tempat tinggal mereka. Anita et al. (2013) mengungkapkan halaman masjid merupakan ruang publik yang digunakan oleh warga untuk kegiatan insidental atau dilakukan hanya pada kesempatan atau waktu tertentu. Halaman masjid biasa digunakan oleh penghuni laki-laki untuk bermain tenis meja di malam hari, selain digunakan sebagai tempat ngobrol pada sore hari sehabis menunaikan sholat. Pengguna halaman masjid adalah penghuni berusia sekitar 31-40 tahun. Mereka umumnya menghabiskan waktu sekitar 1-2 jam sehari dengan frekuensi 2-3 kali dalam seminggu. Gambaran ini menunjukkan sense of community yang terbentuk di halaman masjid tidak terlalu tinggi, karena halaman masjid maupun masjid biasa digunakan untuk kegiatan keagamaan.

\subsection{Pembahasan}

Di kampung kota yang padat dan tidak terencana, maka ruang-ruang publik yang terbentuk berasal dari ruang-ruang terbuka yang ada. Di Kampung Kali Apuran, gang depan rumah, halaman masjid, halaman sekolah, dan area tepi sungai digunakan sebagai ruang kegiatan dan berinteraksi sosial oleh penghuninya, sehingga dapat memfasilitasi terbangunnya sense of community di antara mereka. Dengan adanya sense of community dalam komunitas terwujud ikatan yang akan mempermudah bagi upaya pemeliharaan dan penataan jenis ruang publik tersebut. Ruang yang dijaga, dirawat, dan dipelihara dengan baik akan memfasilitasi kegiatan antar penghuni yang dapat merawat ikatan yang ada. Jadi, tampak adanya kaitan timbal balik antara ketersediaan ruang publik dengan sense of community warga penghuni kampung kota.

Terdapat berbagai jenis kegiatan yang dilakukan di ruang-ruang publik di Kampung Kali Apuran. Lama/durasi dan frekuensi kegiatan dilakukan yang melibatkan warga dari berbagai usia dan kelamin, mulai anak-anak, ibu rumah tangga dan bapakbapak. Hal ini menunjukkan pentingnya kehadiran ruang-ruang publik di kampung kota. Dalam interaksi yang terjadi pada ruang-ruang publik tersebut yang melibatkan berbagai golongan usia warga menunjukkan terbentuknya ikatan yang mempertinggi sense of community penghuni kampung kota. Ruang yang dijaga dan dipelihara akan menjaga ikatan yang terbentuk oleh adanya ruang tersebut. Ruang publik yang berkualitas akan menciptakan rasa kebersamaan dan memelihara kesehatan psikologis dan sosial masyarakat. Jenis ruang publik yang digunakan merupakan hasil kesepakatan diperlukan untuk memaksimalkan fungsi sosial ruang publik di kampung kota dalam memperkuat rasa kebersamaan di dalamnya.

Dalam penelitiannya, Kristiani dan Yuliastuti (2013) mengungkapkan rasa kebersaman yang tinggi terjadi pada jalan yang sempit, yaitu berkisar 1,54,5 meter, sedangkan tingkat rasa kebersamaan yang rendah terjadi pada jalan yang lebih luas, yaitu berkisar 4-7 meter. Dalam kasus Kampung Kali Apuran menunjukan bahwa lebar gang depan rumah berkisar 1-1,5 meter dan memiliki tingkat sense of community sedang dengan persentase $53,7 \%$, kemudian lebar jalan pada area tepi sungai memiliki lebar sekitar 5-7 meter memiliki tingkat sense of community sedang dengan persentase $74,1 \%$. Hal ini dapat dipengaruhi karena area tepi sungai selain untuk mewadahi kegiatan sehari-hari seperti berbincang-bincang, juga dapat mewadahi kegiatan yang melibatkan banyak warga.

Hasil penelitian menunjukkan tingkat sense of community di berbagai jenis ruang publik di Kampung Kali Apuran menunjukkan hasil yang sama. Hal ini menunjukkan demikian pentingnya kehadiran ruang-ruang terbuka publik dalam perkampungan yang padat. Luas unit hunian yang terbatas dan kepadatan hunian yang tinggi menyebabkan terjadi kesesakan hunian yang tinggi. Konflik pemanfaatan ruang dalam hunian 
yang sempit biasanya menyebabkan terjadi tumpahan kegiatan domestik ke luar rumah. Dalam hal ini ruang-ruang terbuka publik dimanfaatkan untuk kegiatan domestik, sehingga konflik pemanfaatan ruang beralih ke ruang publik. Ruang-ruang terbuka publik di samping sebagai sarana membangun sense of community, sebaliknya dapat pula menjadi ruang konflik pemanfaatan antar penghuni kampung. Dengan demikian agar terbangun ke arah yang positif, berupa peningkatan sense of community, maka diperlukan rekayasa sosial berupa peraturan bersama atau kesepakatan tentang pemanfaatan ruang-ruang publik di kampung kota. Dalam hal ini diperlukan adanya pemimpin lokal yang kuat sehingga kepentingan bersama secara adil dalam pemanfaatan ruang publik dapat dijamin.

Dari sisi akademik, penelitian ini berguna untuk penelitian lebih lanjut di antaranya adalah penelitian tentang: atribut ruang publik yang berpengaruh pada sense of community di kampung kota; faktor-faktor yang mempengaruhi pola pemanfaatan ruang terbuka di kampung kota; dan pengukuran sense of community menggunakan index sense of community untuk ruang publik di perumahan yang terencana, baik perumahan horizontal maupun vertikal.

\section{SIMPULAN}

Hasil penelitian menunjukkan bahwa tingkat sense of community pada berbagai jenis ruang publik di Kampung Kali Apuran adalah sama besar. Hal ini menunjukkan bahwa sense of community difasilitasi oleh semua jenis ruang publik yang ada. Ruang publik tersebut menjadi ruang berbagai aktivitas yang dilakukan penghuni kampung dari berbagai usia. Tingkat sense of community masingmasing jenis ruang publik di Kampung Kali Apuran berdasarkan responden memiliki persentase sebagai berikut: tepi sungai $(74,1 \%)$, jalan kecil/gang depan rumah $(53,7 \%)$, halaman sekolah (50\%), dan halaman masjid (40\%). Banyaknya penghuni kampung kota yang beraktivitas memanfaatkan ruang publik memperkuat ikatanikatan yang terbentuk dan mempengaruhi tingkat sense of community pada. Ke empat unsurnya yang meliputi keanggotaan, pengaruh, integritas dan pemenuhan kebutuha, serta hubungan emosional.

\section{DAFTAR PUSTAKA}

Anita, J., Gustya, F., Erawati, L. R., \& Sukma, M. D. (2013). Kajian Terhadap Ruang Publik sebagai Sarana Interaksi Warga di Kampung Muararajeun Lama, Bandung. Reka Karsa, 1(1), 1-12.

Ashadi, A., Anisa, A., \& Nur'aini, R. D. (2018). Kegiatan Ritual Ziarah Makam Habib Husein Alaydrus dan Pengaruhnya terhadap Penggunaan Ruang Publik di Kampung Luar Batang. NALARs, 17(1), 7986. Doi: $10.24853 /$ nalars.17.1.79-86

Francis, J., Giles-Corti, B., Wood, L., \& Knuiman, M. (2012). Creating Sense of Community: The Role of Public Space. Journal of Environmental Psychology, 32(4), 401-409. Doi: 10.1016/j.jenvp.2012.07.002 Hickman, P. (2013). "Third Places" and Social Interaction in Deprived Neighbourhoods in Great Britain. Journal of Housing and the Built Environment, 28(2), 221-236. Doi: 10.1007/s10901-0129306-5

Hutama, I. (2018). The Hidden Structure of Organic Informal-Like Settlements in Jogjakarta City: An Investigation of Socio-Spatial Relationship in an Urban Kampung. IOP Conference Series: Earth and Environmental Science, 158(1), 012003.

Khusairi, A., Nurhamida, Y., \& Masturah, A. N. (2017). Sense of Community dan Partisipasi Warga Kampung Wisata Jodipan. Jurnal RAP (Riset Aktual Psikologi Universitas Negeri Padang), 8(1), 1-122. Doi: 10.24036/rapun.v8i1.7947

Kristiani, M. K., \& Yuliastuti, N. (2013). Kajian Bentuk Lingkungan Permukiman Berdasarkan Sense of Community di Kelurahan Dadapsari Semarang. Teknik PWK (Perencanaan Wilayah Kota), 2(3), 578-586.

McMillan, D. W., \& Chavis, D. M. (1986). Sense of Community: A Definition and Theory. Journal of Community Psychology, 14(1), 623.

Mulyandari, H., \& Bhayusukma, M. Y. (2015). Prospek Public Space pada Kampung Susun sebagai Ruang Interaksi Sosial, Ekonomi 
dan Pengembangan Ilmu di Area Bantaran Sungai. Jurnal Teknik Sipil dan Perencanaan, 17(2), 89-98. Doi: 10.15294/jtsp.v17i2.6883

Prabowo, H. (2002). Aplikasi Sistem Informasi Geografi pada Perubahan Sosial dan Spasial Kampung Kota Jakarta (Studi Kasus pada Kampung Pasar Minggu, Jakarta Selatan). Proceedings, Komputer dan Sistem Intelejen (KOMMIT 2002) from http://repository.gunadarma.ac.id/id/eprin $\mathrm{t} / 612$.

Putera, Y. A. (2014). Ambiguitas Ruang Kampung Pluis Jakarta Selatan dalam Perspektif Privat publik. E Journal Graduate Unpar,1(2), 101110.

Said, R., \& Alfiah, A. (2017). Teritorialitas pada Ruang Publik dan Semi Publik di Rumah Susun (Studi Kasus: Rumah Susun Kecamatan Mariso Makassar). Nature: National Academic Journal of Architecture, 4(2), 128-137. Doi: 10.24252/nature.v4i2a5

Sujatini, S., Soemardi, T. P., Alamsyah, A. T., \& Linda, D. (2015). Temporary Public Open Space as a Spatial Product on Social Life of City Kampong Community, Jakarta. International Journal of Engineering and Technology, 7(2), 156.

Sumintarsih, \& Adrianto. (2014). Dinamika Kampung Kota Prawirotaman dalam Perspektif Sejarah dan Budaya. Yogyakarta: Balai Pelestarian Nilai Budaya (BPNB) Daerah Istimewa Yogyakarta.

Talen, E. (2000). Measuring The Public Realm: A Preliminary Assessment of The Link between Public Space and Sense of Community. Journal of Architectural and Planning Research, 344-360.

Widiananda, A. B. (2018). Peranan dan Pemanfaatan Ruang Publik pada Permukiman Kampung Vertikal Rusun Pekunden Kota Semarang. Jurnal Pembangunan Wilayah \& Kota, 14(1), 1- 16. Doi: 10.14710/pwk.v14i1.17996 